University of Wollongong

Research Online

Faculty of Engineering and Information

Faculty of Engineering and Information

Sciences - Papers: Part B

Sciences

2019

\title{
Influences of Load and Microstructure on Tribocorrosion Behaviour of High Strength Hull Steel in Saline Solution
}

Hui Wu

University of Wollongong, hwu@uow.edu.au

Yan Li

University of Wollongong, State Key Laboratory Of Metal Material For Marine Equipment And Application, Ansteel Iron \& Steel Research Institute

Zhou Li

University of Wollongong, z|411@uowmail.edu.au

Xiawei Cheng

University of Wollongong, xiawei@uow.edu.au

Mahadi Hasan

University of Wollongong, mh001@uowmail.edu.au

See next page for additional authors

Follow this and additional works at: https://ro.uow.edu.au/eispapers1

Part of the Engineering Commons, and the Science and Technology Studies Commons

Research Online is the open access institutional repository for the University of Wollongong. For further information contact the UOW Library: research-pubs@uow.edu.au 


\title{
Influences of Load and Microstructure on Tribocorrosion Behaviour of High Strength Hull Steel in Saline Solution
}

\author{
Abstract \\ The tribocorrosion behaviour of two diferent hull steels (namely, EH36 and EH47) was investigated using \\ a ball-on-disk tribometer under varying normal loads from 10 to $100 \mathrm{~N}$ in a $3.5 \mathrm{wt} \% \mathrm{NaCl}$ saline solution. \\ Sliding in pure water was also performed for a comparison purpose. The results indicate that the \\ corrosion products mainly consist of lath lepidocrocite $(\mathrm{Y}-\mathrm{FeOOH})$ with residual $\mathrm{NaCl}$ crystals when \\ sliding against both steels EH36 and EH47 in the saline solution. Tribocorrosion on EH36 (pearlitic steel) \\ shows lower coefcient of friction (COF) values than those obtained in water, while tribocorrosion on EH47 \\ (bainitic steel) leads to higher COF values instead. The former is due to the formation of considerable \\ hydroxide particulates and flms with small sizes. In contrast, the latter is ascribed to the ploughing of \\ hydroxides with smaller amounts and bigger sizes. In particular, the synergistic efects of corrosion and \\ wear in tribocorrosion result in much higher total materials degradation, compared to that obtained \\ through pure mechanical wear in water. \\ Disciplines \\ Engineering | Science and Technology Studies

\section{Publication Details} \\ Wu, H., Li, Y., Li, Z., Cheng, X., Hasan, M., Zhang, H. \& Jiang, Z. (2019). Influences of Load and \\ Microstructure on Tribocorrosion Behaviour of High Strength Hull Steel in Saline Solution. Tribology \\ Letters, 67 124-1-124-12.
}

\section{Authors}

Hui Wu, Yan Li, Zhou Li, Xiawei Cheng, Mahadi Hasan, Hongmei Zhang, and Zhengyi Jiang 


\section{Influences of load and microstructure on tribocorrosion behaviour of high strength hull steel in saline solution}

Hui $\mathrm{Wu}^{\mathrm{a}^{*}}$, Yan $\mathrm{Li}^{\mathrm{a}}$ b, c, Yao $\mathrm{Lu}^{\mathrm{a}}$, Zhou Li ${ }^{\mathrm{a}}$, Xiawei Cheng ${ }^{\mathrm{a}}$, Mahadi Hasan ${ }^{\mathrm{a}}$, Hongmei Zhang ${ }^{\mathrm{d}^{*}}$, Zhengyi Jiang, ${ }^{\text {a }}{ }^{*}$

${ }^{a}$ School of Mechanical, Materials, Mechatronic and Biomedical Engineering, University of Wollongong, Wollongong, NSW 2522, Australia

${ }^{\mathrm{b}}$ State Key Laboratory of Metal Material for Marine Equipment and Application, Liaoning, Anshan, 114009, China

${ }^{c}$ Ansteel Iron \& Steel Research Institute, Anshan, 114009, Liaoning, China

d School of Materials and Metallurgy, University of Science and Technology Liaoning, Anshan 114051, China

Abstract: The tribocorrosion behaviour of two different hull steels (namely, EH36 and EH47) was investigated using a ball-on-disk tribometer under varying normal loads from 10 to $100 \mathrm{~N}$ in a $3.5 \mathrm{wt} \%$ $\mathrm{NaCl}$ saline solution. Sliding in pure water was also performed for a comparison purpose. The results indicate that the corrosion products mainly consist of lath lepidocrocite $(\gamma-\mathrm{FeOOH})$ with residual $\mathrm{NaCl}$ crystals when sliding against both steels EH36 and EH47 in the saline solution. Tribocorrosion on EH36 (pearlitic steel) shows lower coefficient of friction (COF) values than those obtained in water, while tribocorrosion on EH47 (bainitic steel) leads to higher COF values instead. The former is due to the formation of considerable hydroxide particulates and films with small sizes. In contrast, the latter is ascribed to the ploughing of hydroxides with smaller amounts and bigger sizes. In particular, the synergistic effects of corrosion and wear in tribocorrosion result in much higher total materials degradation, compared to that obtained through pure mechanical wear in water.

Keywords: Hull steel; Tribocorrosion; Corrosive wear; Saline solution

*Corresponding authors.

E-mail addresses: hwu@uow.edu.au, lilyzhm68@163.com,jiang@uow.edu.au 


\section{Introduction}

Hull steels are often subjected to harsh and complex environmental conditions that expedite their degradation, especially when suffering external forces exerted by waves, wind and ocean currents. Mechanical wear is thus generated on the contact surface of hull steel, leading to continuous damage and loss of material. Additionally, corrosion is another important factor that aggravates material loss in marine media. When wear and corrosion occur simultaneously, the abrasive corrosive wear is known as tribocorrosion [1]. Tribocorrosion is a main failure cause of hull steel components in offshore applications due to the synergistic effect of mechanical wear and corrosiveness in seawater [2]. It enables a greater loss of material than that when wear or corrosion takes place individually [3]. In reality, total material loss during tribocorrosion consists of the mechanical wear without corrosion, the corrosion without wear, and the sum of the interactions between the wear and the corrosion [4].

Study on tribocorrosion behaviour of material generally involves coefficient of friction (COF) caused and wear volume generated in a saline solution by use of ball/pin-on-disk tribo-testing configuration, which is connected with an electrochemical workstation. Up to date, although great efforts have been made to investigate the tribocorrosion behaviour of steel in saline solution, some research findings are still contradictory. For instance, Liu et al. [1] used a zinc plate as a cathodic protection material clamped underneath the steel disk, and then conducted pin-on-disk tribocorrosion tests in seawater, deionised water and ethanol. They found that the COF and the wear rate in seawater were the highest and smallest, respectively, among three liquids. Ortega et al. [2] investigated the effect of temperature on tribocorrosion behaviour of high strength low-alloy steels in seawater. They revealed that a larger amount of corrosion products (ferrous oxides) produced at a higher temperature led to a higher COF. Similar results were obtained by Zhang et al. [4]. They pointed out that the corrosion products formed under tribocorrosion brought forth higher COF than that caused under pure mechanical wear. However, some researchers have drawn completely opposite conclusions. For example, Bateni et al. [5] performed wear and corrosive wear tribological tests in the presence of $\mathrm{NaCl}$ solution and dry condition using medium carbon steel and 304 stainless steel. They observed that the surface oxide layer formed under corrosive condition acted as lubricant to reduce COF for both steels. Besides, Murkute et al. [6] examined the effects of corrosion-wear and wear-corrosion on the overall degradation of a dual phase steel and a mild steel when corrosion and wear happened alternatively. They reported that the rust particles produced in $\mathrm{NaCl}$ solution gave rise to third-body abrasive wear mechanism, which resulted in a decreased COF.

To solve the contradiction mentioned above, some factors that may influence the tribocorrosion behaviour

of hull steel can be considered, including load [4, 7, 8], velocity [9-11], temperature [2, 12], microstructure [13-15], atmosphere [3], and hardness [16, 17]. In general, hardness plays a critical role in the frictional 
and wear resistance of steel materials, even though other factors such as load and microstructure are also of vital importance in marine environment. In the present work, to avoid the main influence of hardness on the tribocorrosion behaviour of hull steel, two types of hull steels with similar hardness values but different microstructures were employed to investigate their tribocorrosion behaviour in a $3.5 \mathrm{wt} \% \mathrm{NaCl}$ saline solution under different normal loads. Tribocorrosion mechanisms involved during sliding in the saline solution were proposed according to the characterisation of surface morphology in the wear track.

\section{Experimental details}

\subsection{Materials}

A ball made of martensitic stainless steel (MSS) 440 and two different high strength hull steel disks (EH36 and EH47) were used as the friction pairs in a ball-on-disk tribometer. The chemical compositions of the ball and disk materials are listed in Table 1. The ball being used had a diameter of $9.5 \mathrm{~mm}$ and a surface roughness of $0.02 \mu \mathrm{m}$ in $\mathrm{R}_{\mathrm{a}}$. The hardness of the ball was around $740 \mathrm{HV}$. The disks were machined to a dimension of $\varnothing 40 \mathrm{~mm} \times 8 \mathrm{~mm}$ and then grinded with a uniform surface roughness of $0.09 \mu \mathrm{m}$ in $\mathrm{R}_{\mathrm{a}}$. The mechanical properties and surface microstructures of these two disks are shown in Table 2 and Fig. 1, respectively. It can be seen that EH36 consists of ferrite and pearlite, while EH47 is composed of ferrite and bainite. Regardless of their differences in chemical compositions and microstructures, EH36 and EH47 have almost identical hardness values, showing approximately 206.6 and $205.8 \mathrm{HV}$, respectively. Surface morphologies and 3D profiles of the friction pairs are shown in Fig. 2. It is observed that the ball surface is relatively smooth, while the disks have apparent scratches on their surfaces. The rough surfaces were obtained in accordance with the actual surface conditions of steels.

Table 1 Chemical compositions of the ball and disk materials (wt\%).

\begin{tabular}{llllllll}
\hline Materials & $\mathrm{C}$ & $\mathrm{Si}$ & $\mathrm{Mn}$ & $\mathrm{Cr}$ & $\mathrm{Ni}$ & $\mathrm{Mo}$ & $\mathrm{Nb}+\mathrm{V}+\mathrm{Ti}$ \\
\hline Ball-MSS 440 & 1.0 & 0.3 & 0.5 & 17.5 & 0.5 & 0.5 & - \\
Disk-EH36 & 0.09 & 0.15 & 1.5 & - & - & - & $<0.1$ \\
Disk-EH47 & 0.07 & 0.2 & 1.42 & 0.07 & 0.79 & - & 0.06
\end{tabular}

Table 2 Mechanical properties of the disk materials.

\begin{tabular}{lllll}
\hline Materials & Hardness/HV & Yield strength/MPa & Tensile strength/MPa & Elongation/\% \\
\hline EH36 & $206.6 \pm 3.1$ & 355 & $490-600$ & 21 \\
EH47 & $205.8 \pm 1.8$ & 390 & $600-690$ & 20 \\
\hline
\end{tabular}



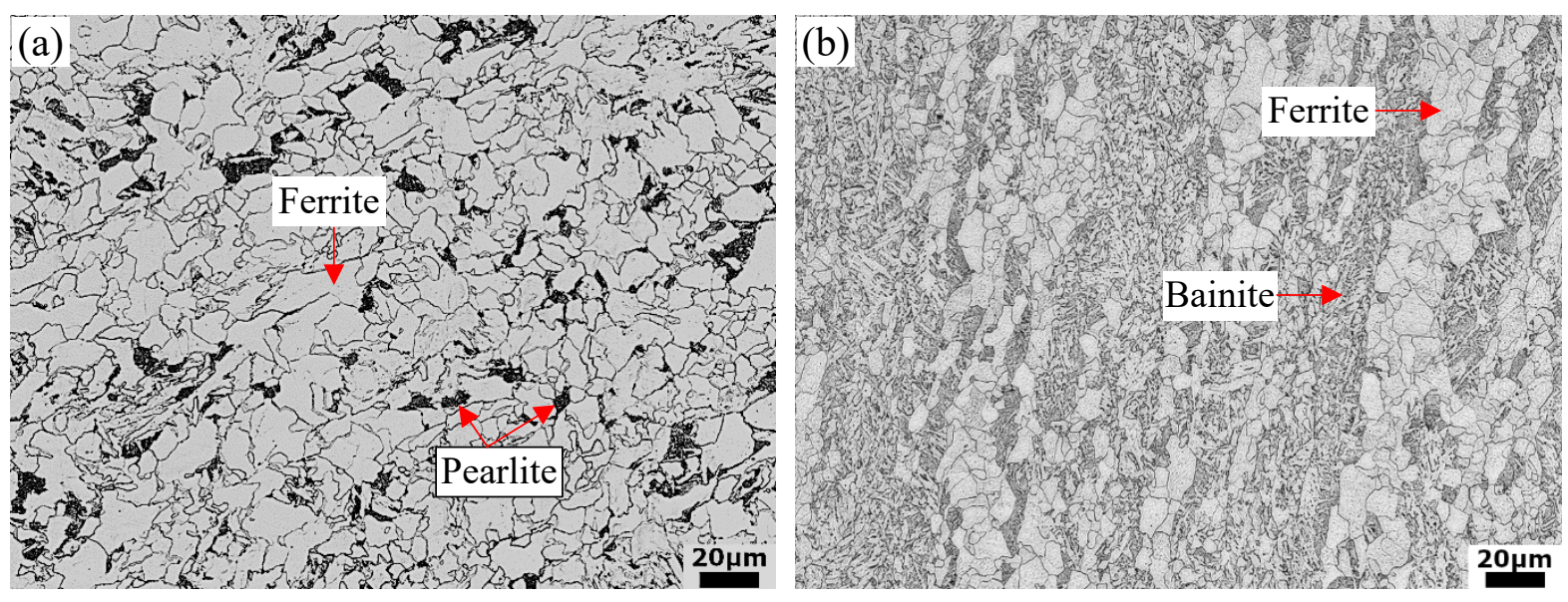

Fig. 1 Surface microstructures of hull steel disks: (a) EH36 and (b) EH47. 

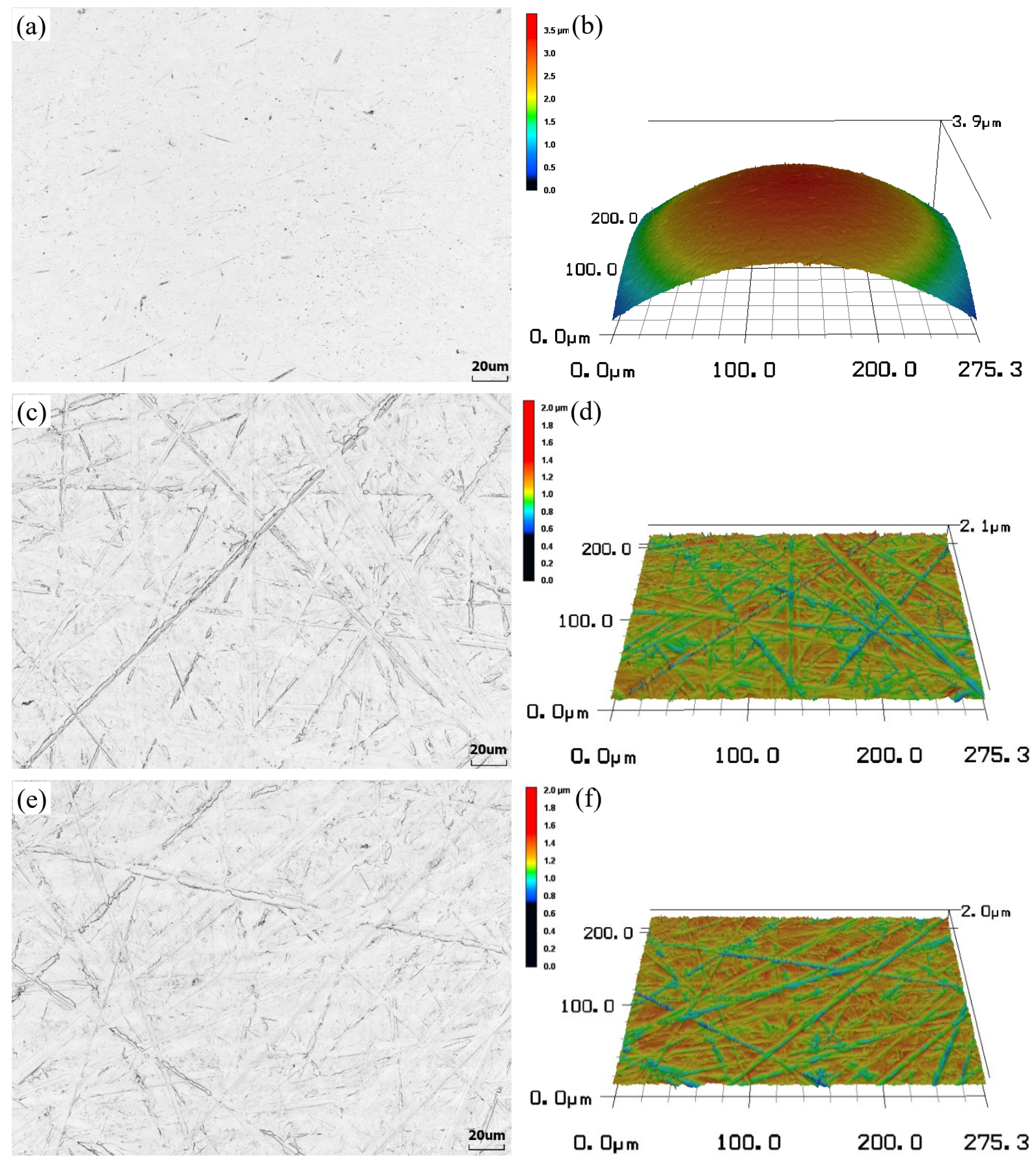

Fig. 2 Surface morphologies and 3D profiles of the friction pairs: (a) and (b) MSS 440 ball; (c) and (d) EH36 disk; (e) and (f) EH47 disk.

The saline solution was facilely prepared by mixing pure sodium chloride $(\mathrm{NaCl})$ into distilled water with a solute concentration of $3.5 \mathrm{wt} \%$. For comparison, testing condition with pure distilled water was also used to represent the case of pure mechanical wear without corrosion in an approximate way. 


\subsection{Electrochemical tests}

Polarisation curve measurements for both steels EH36 and EH47 were performed using a Gill AC potentiostat (ACM instrument, Cumbria, UK) with a sweep rate of $60 \mathrm{mv} / \mathrm{min}$ in a $3.5 \mathrm{wt} \% \mathrm{NaCl}$ solution at $20{ }^{\circ} \mathrm{C}$. The electrochemical active surface area of working electrode was kept at $0.2 \mathrm{~cm}^{2}$. Before the electrochemical test, the steel samples were successively subjected to grinding with 500 \# and 1200 \# SiC papers, followed by polishing with different sizes of slurries from $9 \mu \mathrm{m}$ down to $1 \mu \mathrm{m}$.

\subsection{Tribocorrosion tests}

An Rtec MFT-5000 Multi-functional Tribometer was used to measure the coefficient of friction (COF) through a ball-on-disk tribo-testing configuration, as shown in Fig. 3. This configuration being used was consistent to that reported in our previous study [18] where the disk was immersed in a $3.5 \mathrm{wt} \% \mathrm{NaCl}$ saline solution with a fixed volume of $40 \mathrm{ml}$ in each tribocorrosion test. By doing this, the initial experimental conditions could be well controlled. Both the ball and disk were cleaned ultrasonically for 5 min before and after each test.

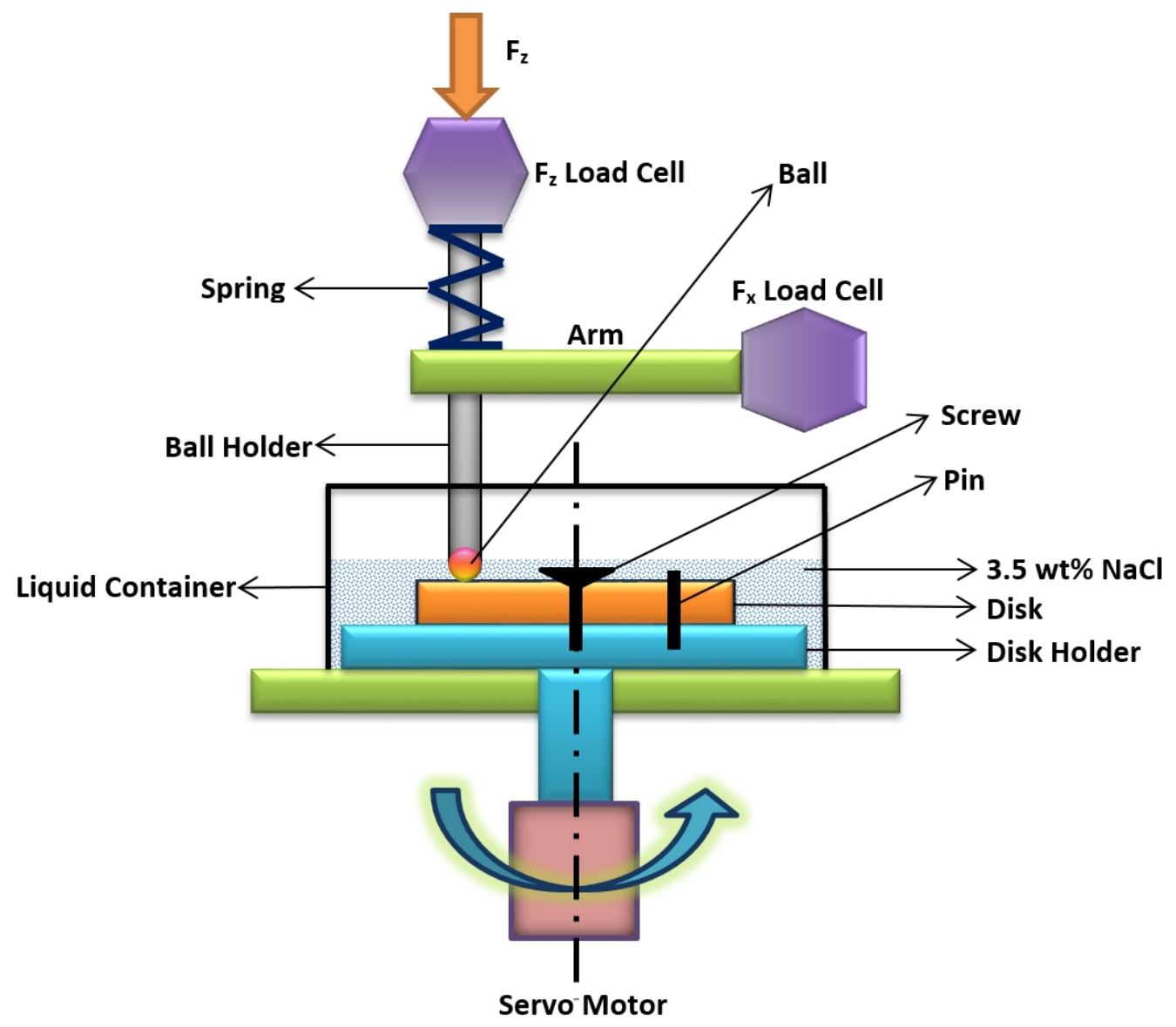

Fig. 3 Schematic diagram of the ball-on-disk configuration used for tribocorrosion tests. 
The tribo-testing conditions employed in this study are shown in Table 3. Varying normal loads of 10, 20, 50 and $100 \mathrm{~N}$ were applied on the ball to slide against the disk for a period of $60 \mathrm{~min}$ in the saline solution. The reason of choosing a relatively long sliding time was to generate sufficient corrosion products that could be collected for further analysis. The linear speed and radius of the wear track were $50 \mathrm{~mm} / \mathrm{s}$ and 14 $\mathrm{mm}$, respectively. It should be noted that a relatively low sliding speed hereby was selected to minimise the hydrodynamic effect on testing results $[19,20]$. During testing, the time histories of COF were recorded. For each condition, the same test was repeated three times to obtain an averaged COF value from the stable stage.

Table 3 Tribo-testing conditions at room temperature.

\begin{tabular}{lllll}
\hline Normal load & Testing duration & Linear speed & Radius of wear track & Saline solution \\
\hline $10,20,50$ and $100 \mathrm{~N}$ & $60 \mathrm{~min}$ & $50 \mathrm{~mm} / \mathrm{s}$ & $14 \mathrm{~mm}$ & $3.5 \mathrm{wt} \% \mathrm{NaCl}$ \\
\hline
\end{tabular}

\subsection{Analytical techniques}

Powder X-ray diffraction (XRD) was performed on a Philips PW1730 conventional diffraction meter with $\mathrm{Cu}-\mathrm{K}_{\alpha}$ radiation to analyse the phase compositions in the corrosion products produced during tribocorrosion test. In order to minimise the influence of $\mathrm{NaCl}$ crystals on detecting the corrosion products, the supernatant of the saline solution collected after tribocorrosion test was replaced with distilled water three times. This process was operated on the condition that all the corrosion products settled down to the bottom, leading to minimum loss of the corrosion products. After that, the sunk corrosion products were dropped onto the surface of a sample holder made of quartz glass, and then dried slowly on a hot plate. It should be noted that a larger amount of corrosion products obtained under $100 \mathrm{~N}$ were used for the phase analysis, which could result in a higher intensity during XRD testing.

The corrosion products were further analysed in terms of morphologies and phase identification using a JEOL model JEM-ARM200F Transmission Electron Microscope (TEM) equipped with an energydispersive spectrometer (EDS).

The wear tracks of the disks after tribocorrosion tests were observed under a KEYENCE VK-X100K 3D Laser Scanning Microscope, from which the 3D profiles of the worn zones were obtained to examine the wear of disks. The wear-corrosion mechanisms were proposed by the use of a JEOL model JSM-6490LV Scanning Electron Microscope (SEM) coupled with an EDS.

\section{Results}

\subsection{Polarisation curve}


Fig. 4 shows the potentiodynamic polarisation curves of steels EH36 and EH47 when immersing in the 3.5 $\mathrm{wt} \% \mathrm{NaCl}$ saline solution. It can be obtained that $\mathrm{EH} 36$ exhibits a higher corrosion rate $\left(0.64 \mathrm{~mA} / \mathrm{cm}^{2}\right)$ than that of EH47 $\left(0.36 \mathrm{~mA} / \mathrm{cm}^{2}\right)$, which indicates that EH36 is more readily corroded in the saline solution compared to EH47.

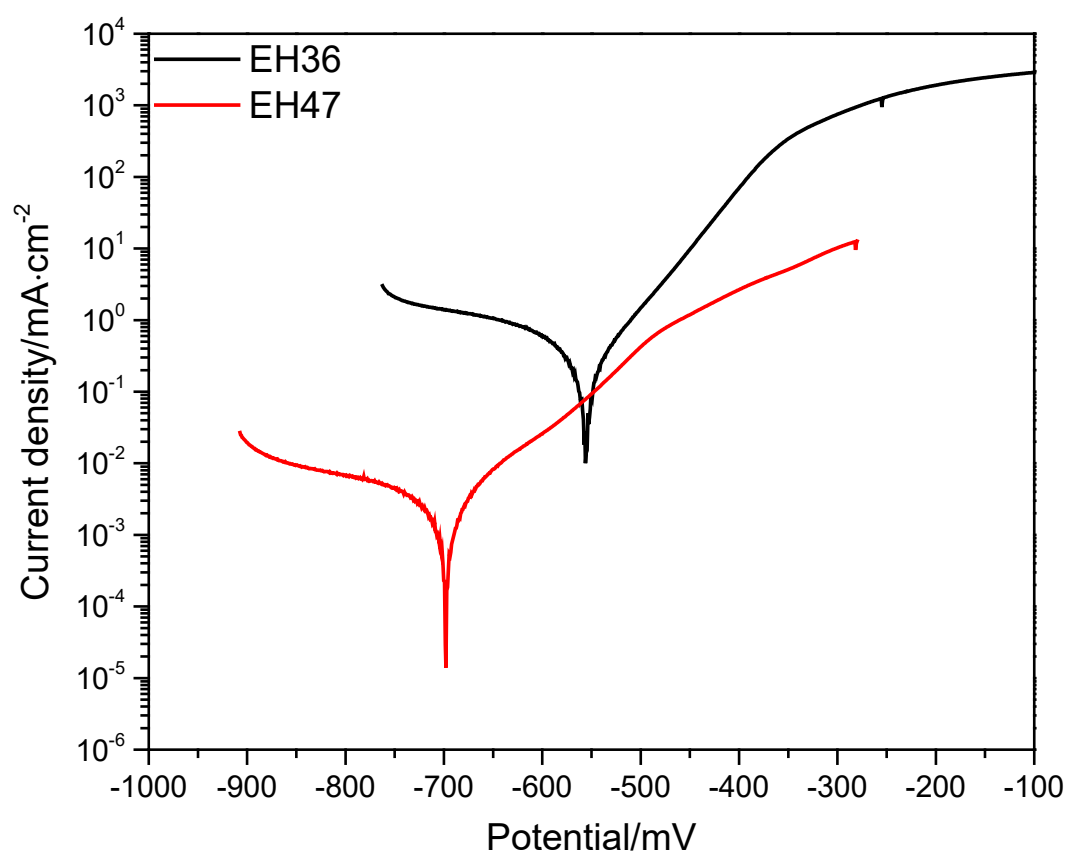

Fig. 4 Potentiodynamic polarisation curves of steels EH36 and EH47 in $3.5 \mathrm{wt} \% \mathrm{NaCl}$ solution.

\subsection{Characterisation of corrosion products}

The XRD patterns of the corrosion products obtained from sliding against EH36 and EH47 disks under a load of $100 \mathrm{~N}$ are shown in Fig. 5. It can be seen that the corrosion products mainly consist of lepidocrocite $(\gamma-\mathrm{FeOOH})$ with residual $\mathrm{NaCl}$ precipitates regardless of the steel being used. The morphologies and phase compositions of the corrosion products are examined using TEM-EDS and selected area electron diffraction (SAED), as illustrated in Figs. 6 and 7. It is evident from Fig. 6a and c that the corrosion products are a mixture of lath iron oxides and lamellar $\mathrm{NaCl}$ crystals, which are consistent with those reported somewhere [21]. According to the SAED patterns displayed in Fig. 6b, the d-spacing values are 0.337, 0.295 and 0.248 $\mathrm{nm}$, respectively, from the first to the third diffraction ring (counted from inside to outside). This corresponds to (1 $\left.2 \begin{array}{ll}1 & 0\end{array}\right),\left(\begin{array}{lll}0 & 1 & 1\end{array}\right)$ and $\left(\begin{array}{lll}0 & 3 & 1\end{array}\right)$ planes successively, indicating the presence of lepidocrocite $(\gamma-$ $\mathrm{FeOOH}$ ) with an orthorhombic crystal structure. The fourth diffraction ring reveals a d-spacing of 0.199 $\mathrm{nm}$, which accords with (2 20 ) plane by searching and comparing with the PDF card of $\mathrm{NaCl}$. As can be seen in Fig. 7, the corrosion products produced when sliding against EH47 disk in $\mathrm{NaCl}$ solution are also predominated by lath $\gamma-\mathrm{FeOOH}$. 


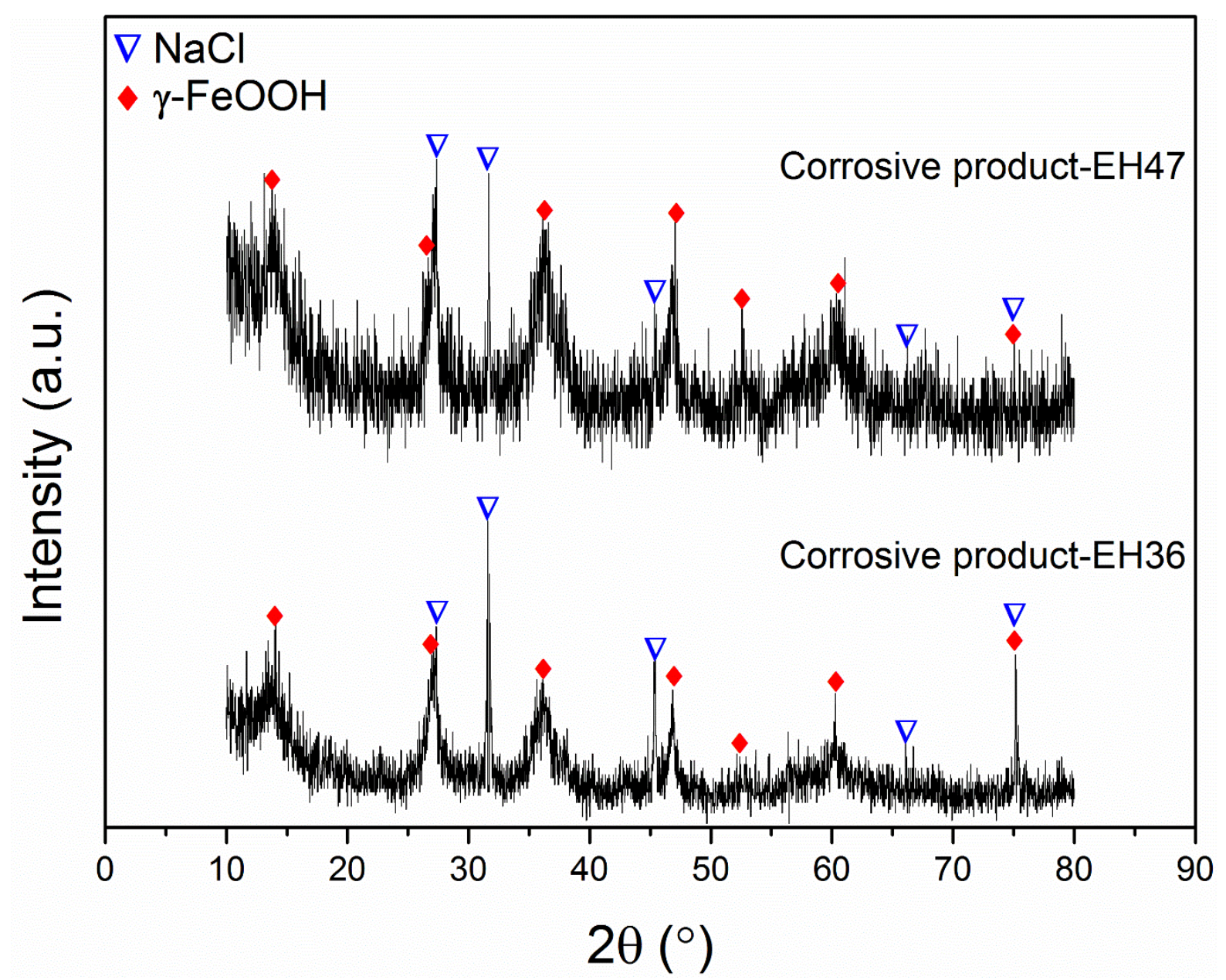

Fig. 5 XRD patterns of corrosion products obtained when sliding against EH36 and EH47 disks under a load of $100 \mathrm{~N}$. 
(a)
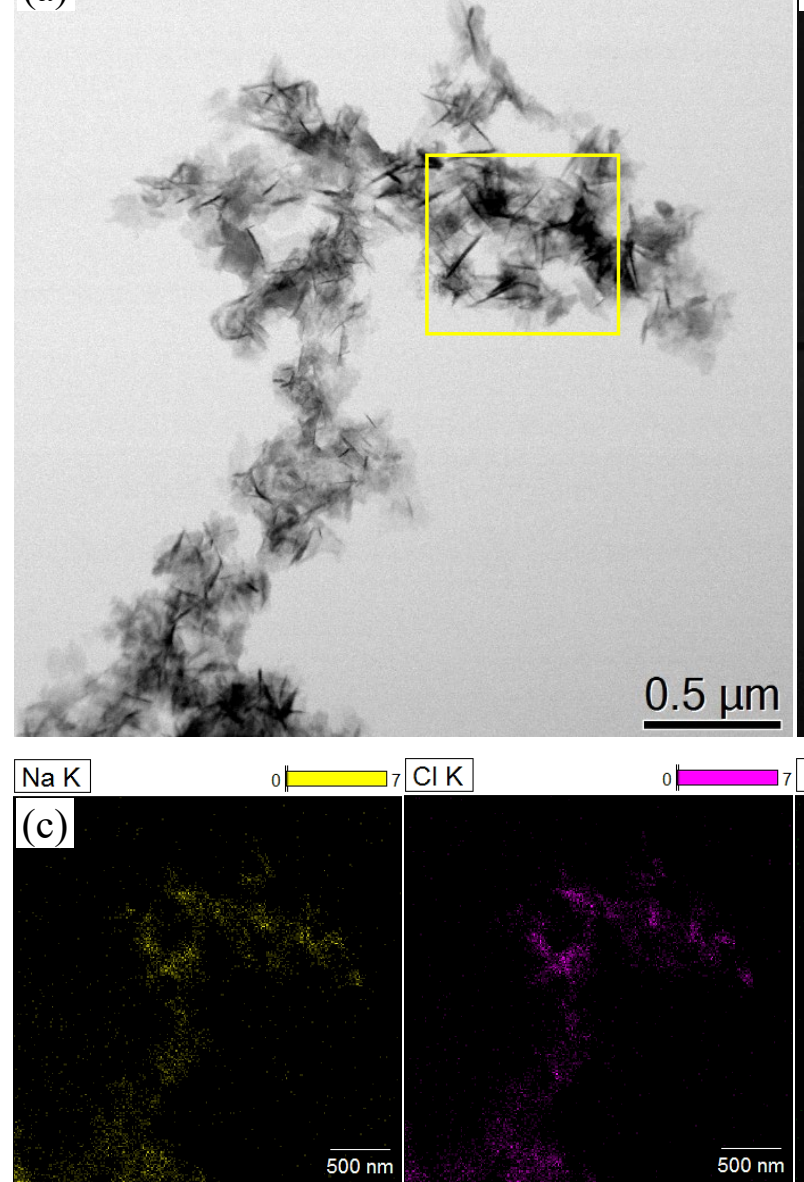

(b)

\section{(1 20$)$}

(0 11 1)

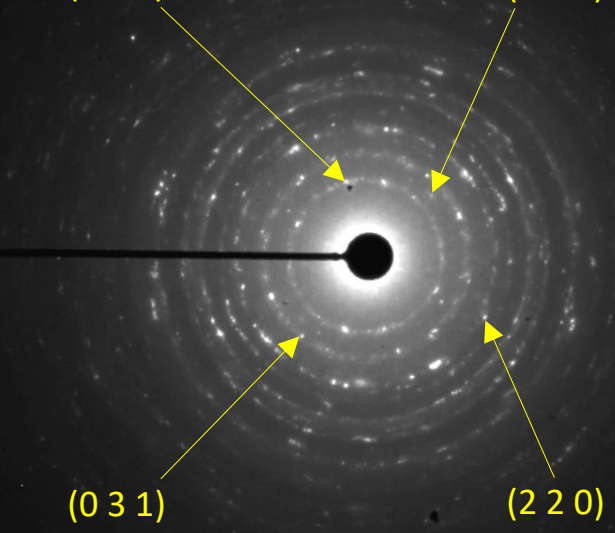

\section{$51 / \mathrm{nm}$}

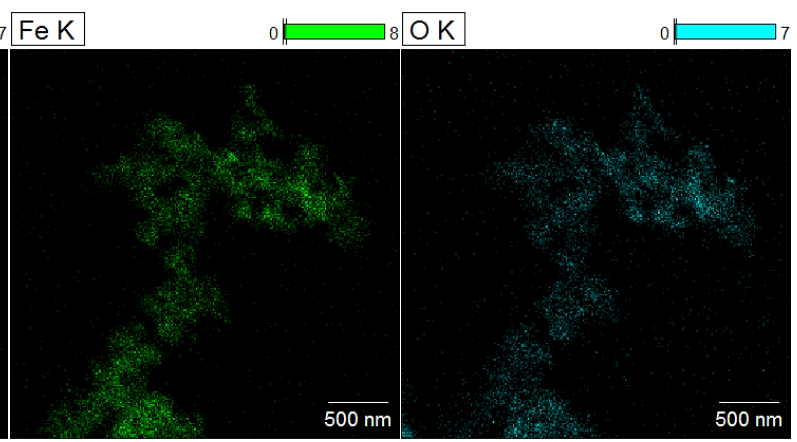

Fig. 6 (a) TEM bright field image of the corrosion products, (b) SAED pattern of the region in (a), and (c) X-ray mappings of (a) when sliding against steel EH36 under a load of $100 \mathrm{~N}$. 


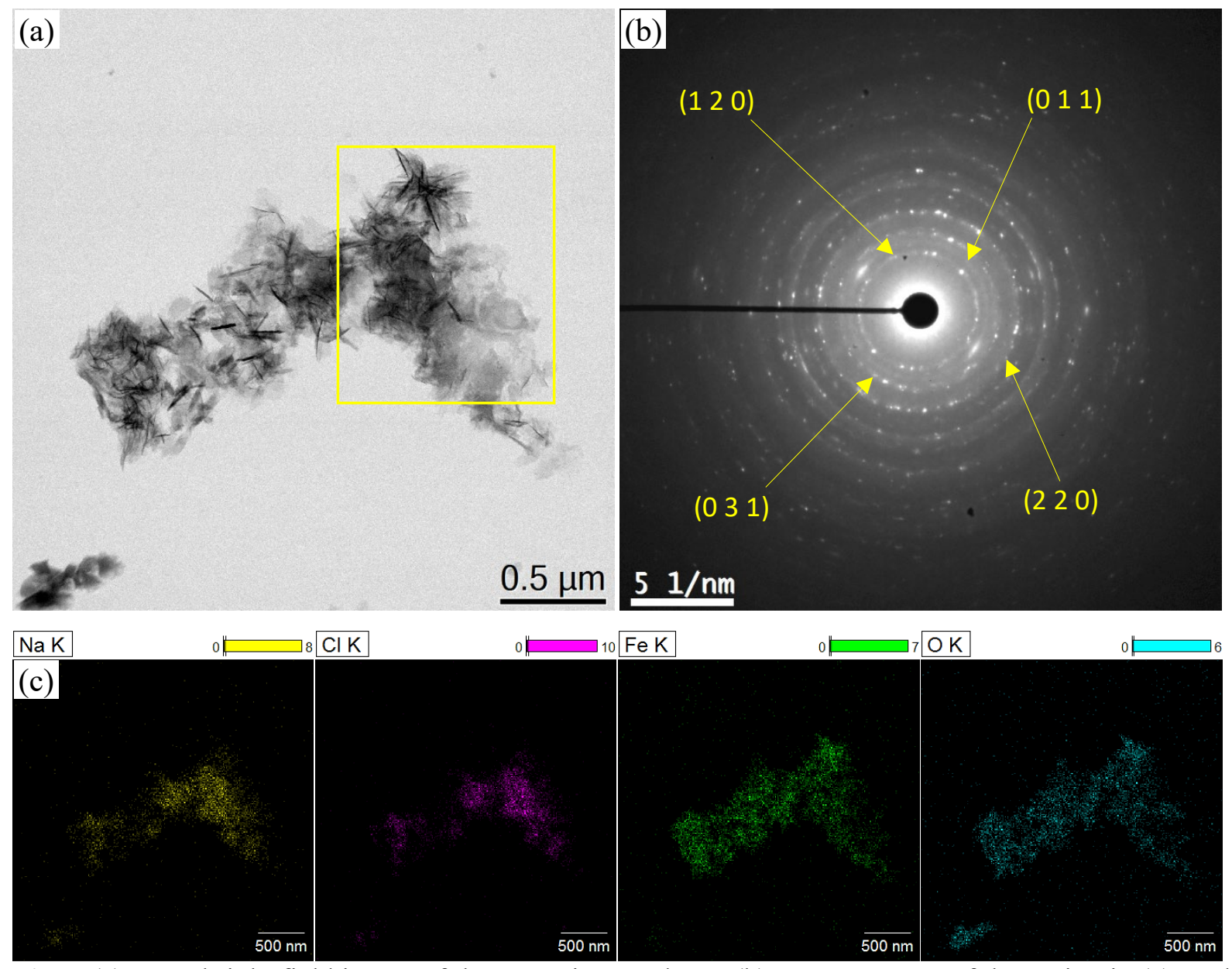

Fig. 7 (a) TEM bright field image of the corrosion products, (b) SAED pattern of the region in (a), and (c) X-ray mappings of (a) when sliding against steel EH47 under a load of $100 \mathrm{~N}$. 


\subsection{Coefficient of friction}

Fig. 8 shows the COF curves over sliding time and averaged COF values obtained from the stable stages of sliding against steel disks under different loads in water and $\mathrm{NaCl}$ solutions. Fig. 8a reveals the variation trend of COF over time when sliding on steel EH36. It is found that the COF curve obtained under $10 \mathrm{~N}$ in water rises continuously in the first $25 \mathrm{~min}$, and then gradually stabilises in the rest of period. When the load increases, however, the running-in periods are limited within $5 \mathrm{~min}$, after which the COF curves tend to reach a constant level until the end of the tests. A similar variation trend of COF curves over time can also be observed in the $\mathrm{NaCl}$ solution. In order to compare the $\mathrm{COF}$ obtained in both water and $\mathrm{NaCl}$ solution, averaged values selected from the stable stages of COF curves are shown in Fig. 8b. It can be seen that the $\mathrm{COF}$ values are smaller in $\mathrm{NaCl}$ solution, compared with those generated in water when sliding against steel EH36 under the same normal load. Beyond that, the COF decreases continuously with the increase of normal load from 10 to $100 \mathrm{~N}$ in both water and $\mathrm{NaCl}$ solutions. In particular, the COF drops sharply with the normal load increasing from 10 to $20 \mathrm{~N}$ in water, which may be attributed to the formation of a larger amount of wear debris, suggesting a third-body lubrication [22, 23]. Another interesting phenomenon is that there exists insignificant difference in $\mathrm{COF}$ between water and $\mathrm{NaCl}$ with the increase of normal load, which will be discussed later. In comparison to the case occurred when sliding on steel EH47, the running-in period of sliding in water under $10 \mathrm{~N}$ lasts for around $32 \mathrm{~min}$, which is longer than that of sliding on steel EH36 (see Fig. 8c). Other running-in periods can also be limited within 5 min. There is also a declining trend towards the $\mathrm{COF}$ variation with increasing the normal load both in water and $\mathrm{NaCl}$ solutions, as shown in Fig. 8d. However, the COF exhibits a higher level in $\mathrm{NaCl}$ than that in water regardless of the normal load being applied. It is worth noting that sliding on steel EH36 brings forth lower $\mathrm{COF}$ values than that of sliding on steel $\mathrm{EH} 47 \mathrm{in} \mathrm{NaCl}$ solution under the same tribo-testing conditions. 

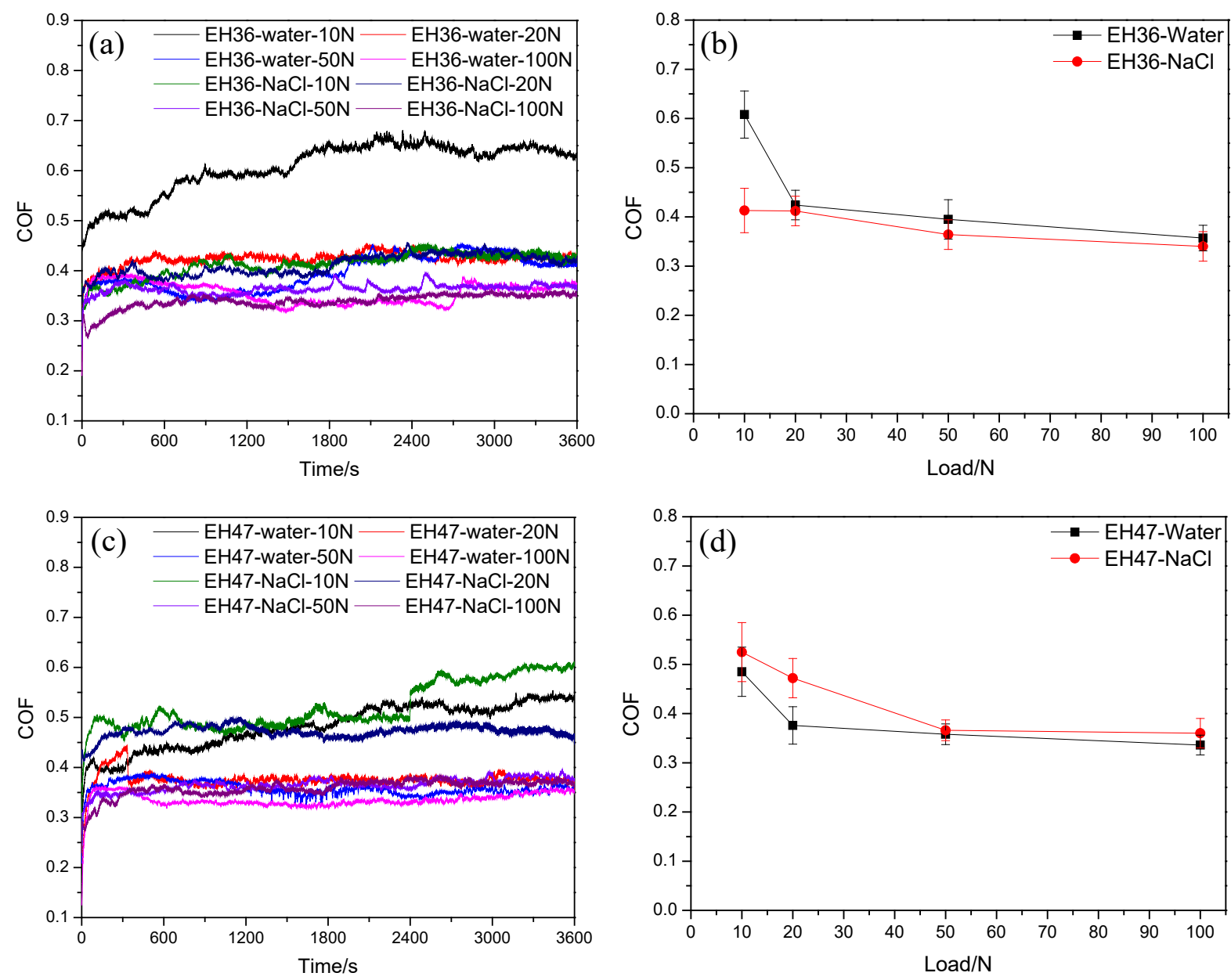

Fig. 8 COF curves over sliding time using (a) EH36 and (c) EH47, and averaged COF values obtained from the stable stages of sliding against (b) EH36 and (d) EH47 under different loads in water and $\mathrm{NaCl}$ solutions.

\subsection{Wear of disk}

Fig. 9a, c and e demonstrate the 3D images and corresponding cross-sectional profiles of the disk wear obtained when sliding against $\mathrm{EH} 36$ disks in $\mathrm{NaCl}$ solution under loads of 10,50 and $100 \mathrm{~N}$, respectively. It reveals that the disk wear aggravates with the increase of normal load. A particular phenomenon is that the bumps in red are distributed inside the wear tracks. These bumps are supposed to be corrosion products, which will be discussed in SEM images. In contrast, the bumps are rarely found in the wear tracks of EH47 disks, as illustrated in Fig. 9b, d and f. The disk wear, however, is much higher than that obtained in EH36 under the same tribo-testing conditions. Increasing the normal load applied on EH47 disks, similarly, would result in increased disk wear. Fig. 10 compares the total wear of disks between the use of water and $\mathrm{NaCl}$ solution under different loads. It is obvious that tribocorrosion leads to more severe disk wear than that obtained under pure mechanical wear in water. 

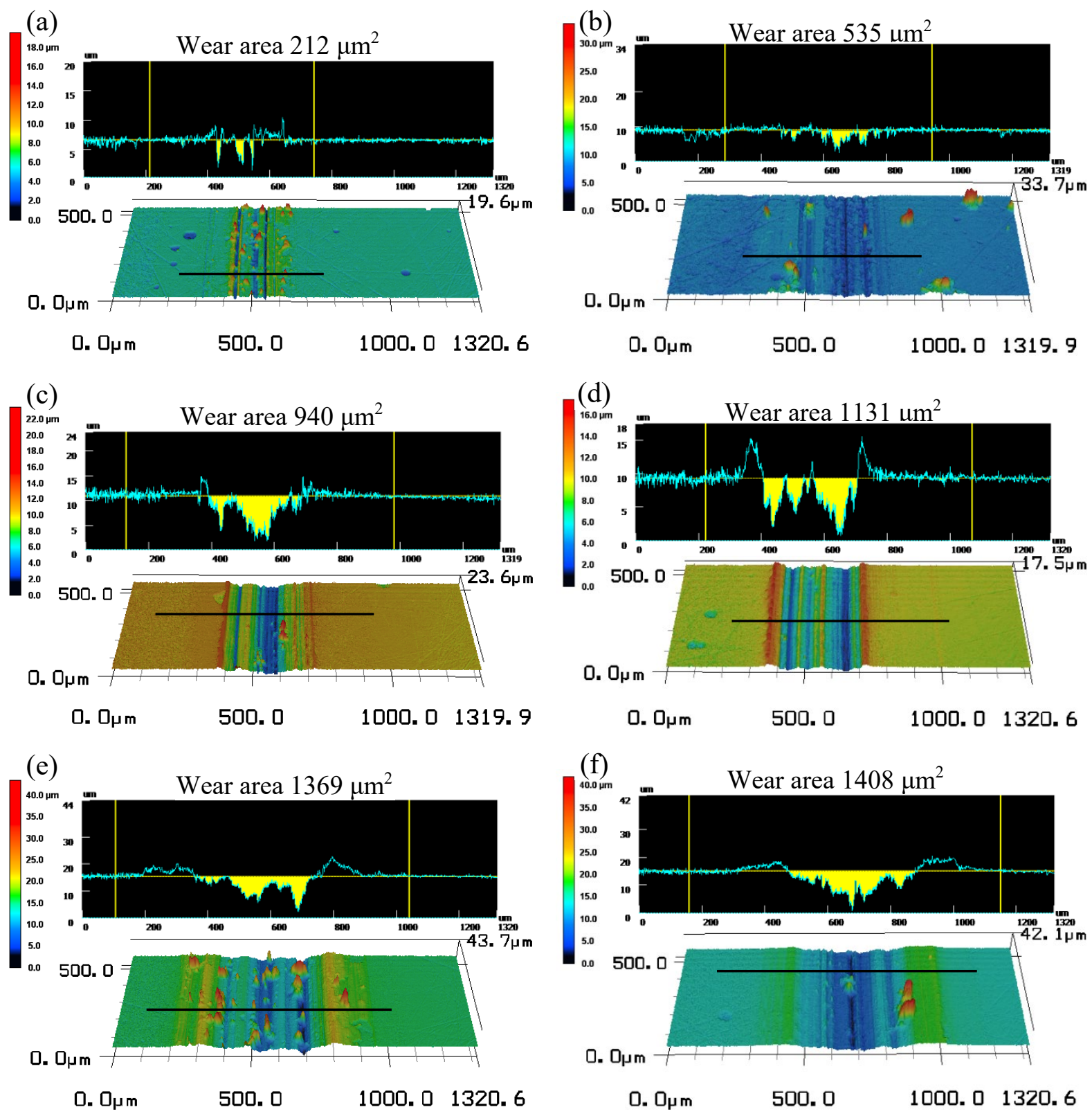

Fig. $93 \mathrm{D}$ images and corresponding cross-sectional profiles of the disk wear obtained in $\mathrm{NaCl}$ solution using EH36 (a, c and e), and EH47 (b, d and f) under loads of (a, b) 10, (c, d) 50 and (e, f) $100 \mathrm{~N}$. 


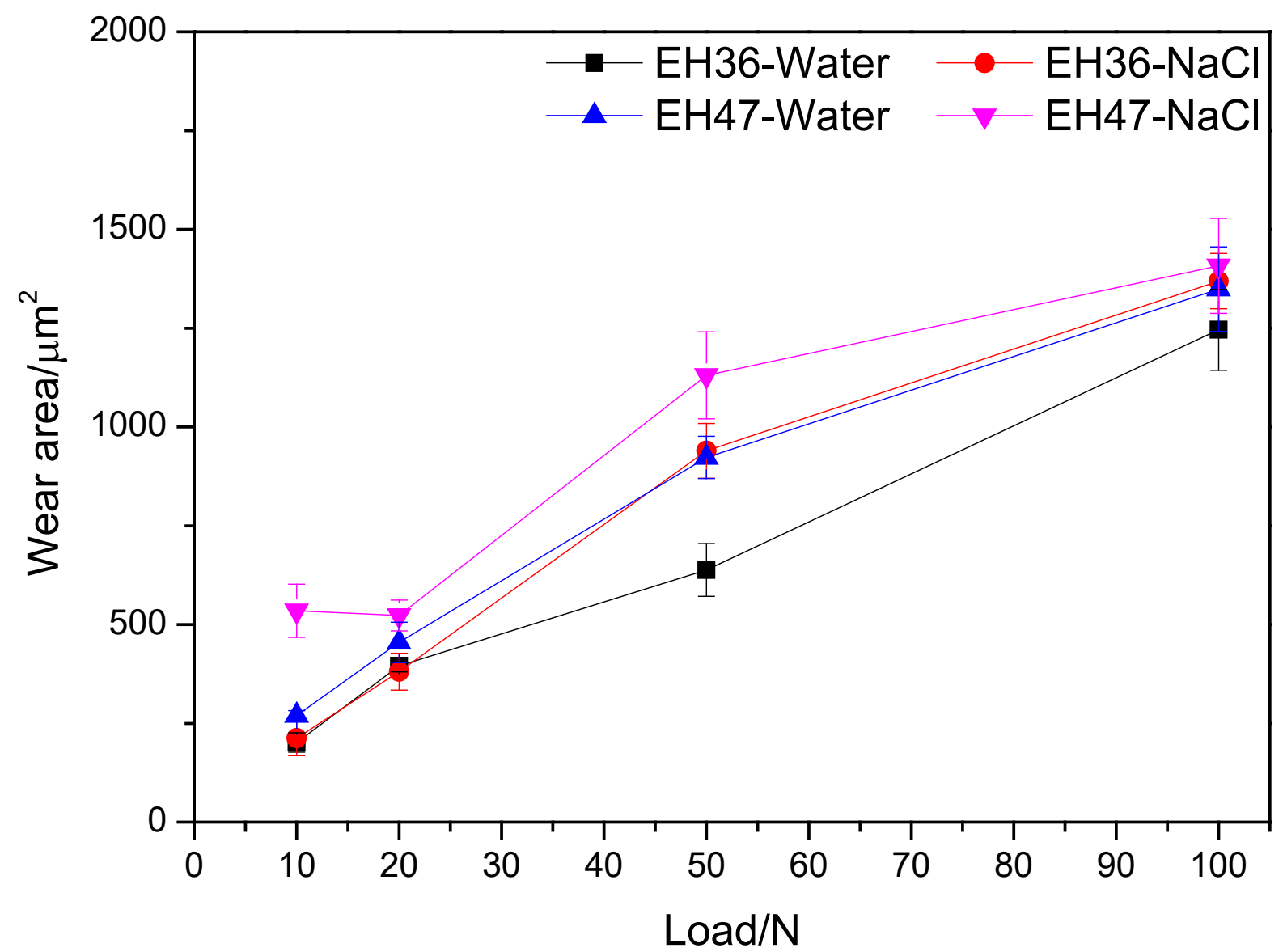

Fig. 10 Wear areas of disks under different loads in water and $\mathrm{NaCl}$ solutions.

\section{Discussion}

Fig. 11 presents the SEM images and X-ray mappings of the worn surfaces of steel EH36 under different loads in $\mathrm{NaCl}$ solution. It is found from Fig. 11a that corrosion pits and scratches are generated inside the wear track after sliding with $10 \mathrm{~N}$, although a small amount of corrosion products $(\gamma-\mathrm{FeOOH})$ can also be observed. Therefore, pitting corrosion is the dominant form of corrosion, and abrasive wear prevails as the corrosion products cannot completely separate the ball and disk during the sliding process. However, the presence of $\gamma$-FeOOH contributes to a lower $\mathrm{COF}$ than that obtained under pure mechanical wear in water (see Fig. 8b), while the pitting corrosion expedites the degradation of disk materials, leading to an aggravated disk wear (see Fig. 10). With increasing the normal load to 50 N, it is evidently shown in Fig. $11 \mathrm{~b}$ that $\gamma-\mathrm{FeOOH}$ bumps appear instead of forming corrosion pits. Apart from that, the corrosion products spread over the wear track, and $\gamma-\mathrm{FeOOH}$ films are thus formed. Such hydroxide film behaves as an intermediate layer on the disk surface, which decreases the COF to a larger extent than that obtained under $10 \mathrm{~N}$ [24]. The decrease in COF with increasing normal load is also ascribed to the flattened debris [7] or 
the smoothing of surface at high load as reported elsewhere $[8,25]$. A further increase in normal load to $100 \mathrm{~N}$ in $\mathrm{NaCl}$ solution is inclined to smash $\gamma$-FeOOH bumps and films into particulates and flakes (see Fig. 11c), which may further decrease the COF. Meanwhile, an increase in normal load results in increased amounts of wear debris in water. These wear debris acting as third-body lubrication in water could be comparable to the lubrication effect of $\gamma$-FeOOH produced in the $\mathrm{NaCl}$ solution when the normal load increases up to $100 \mathrm{~N}$. Therefore, the COF difference between water and $\mathrm{NaCl}$ environment at higher loads becomes smaller (see Fig. 8b). As the disk suffers from wear and corrosion simultaneously in the $\mathrm{NaCl}$ solution, the mechanical and corrosion-accelerated wear lead to much more disk degradation, compared with that obtained in water. With the increase of normal load, the synergistic effects of wear and corrosion become increasingly significant, and therefore resulting in increased disk wear.
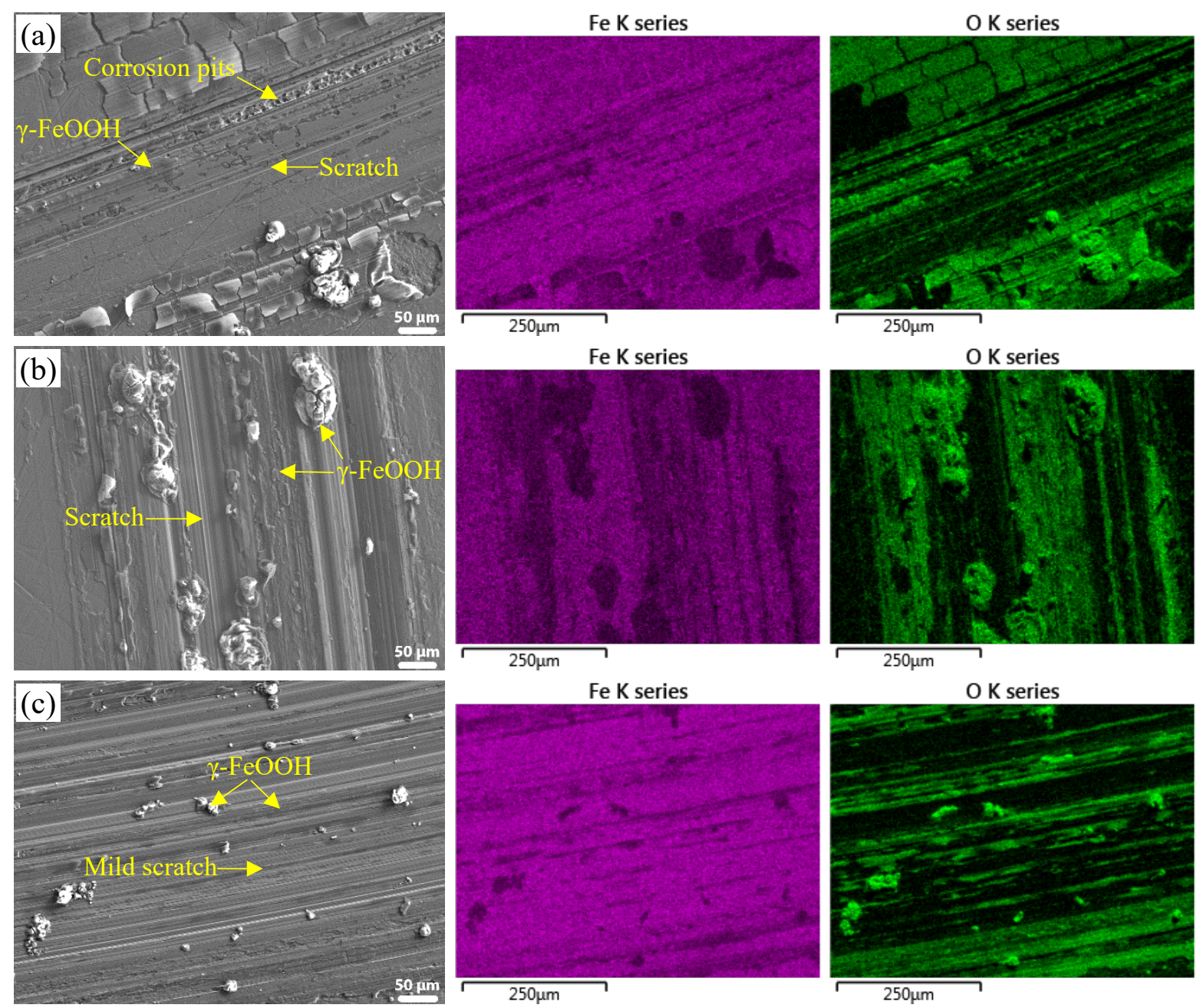

Fig. 11 SEM images and X-ray mappings of the worn surfaces of steel EH36 under loads of (a) 10 N, (b) $50 \mathrm{~N}$, and (c) $100 \mathrm{~N}$ in $3.5 \mathrm{wt} \% \mathrm{NaCl}$ solution. 
Fig. 12 shows the SEM images and X-ray mappings of the worn surfaces of steel EH47 under different loads in $\mathrm{NaCl}$ solution. It can be seen from Fig. 12a that there are a large amount of corrosion pits inside the wear track where apparent corrosive wear occurs during the sliding process under $10 \mathrm{~N}$. The spalling of disk substrate caused by corrosive wear gives rise to relatively rough wear track, and hence brings forth a higher COF than that obtained in water. Fig. $12 \mathrm{~b}$ reveals the presence of severe scratches with similar sizes to the $\gamma$-FeOOH bumps when sliding under $50 \mathrm{~N}$, suggesting a typical characteristic of abrasive wear. Additionally, no $\gamma$-FeOOH films are deposited inside the wear track, which is different from the case occurred when sliding on steel EH36 (see Fig. 11b). When the normal load increases from 50 to 100 N, $\gamma$ FeOOH produced during tribocorrosion becomes smaller, though the severe scratches still emerge due to the abrasive wear (see Fig. 12c). Another phenomenon is that there exists $\gamma$-FeOOH-depleted region inside the wear track, let alone the formation of $\gamma-\mathrm{FeOOH}$ films, as shown in Fig. 11c.
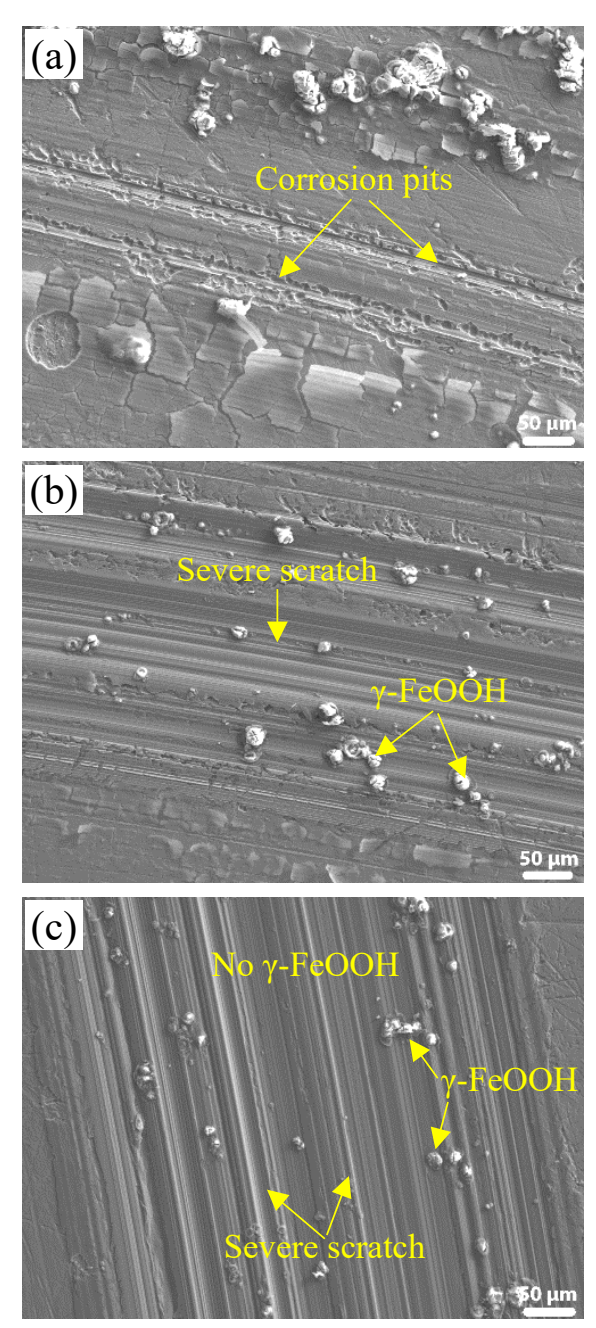
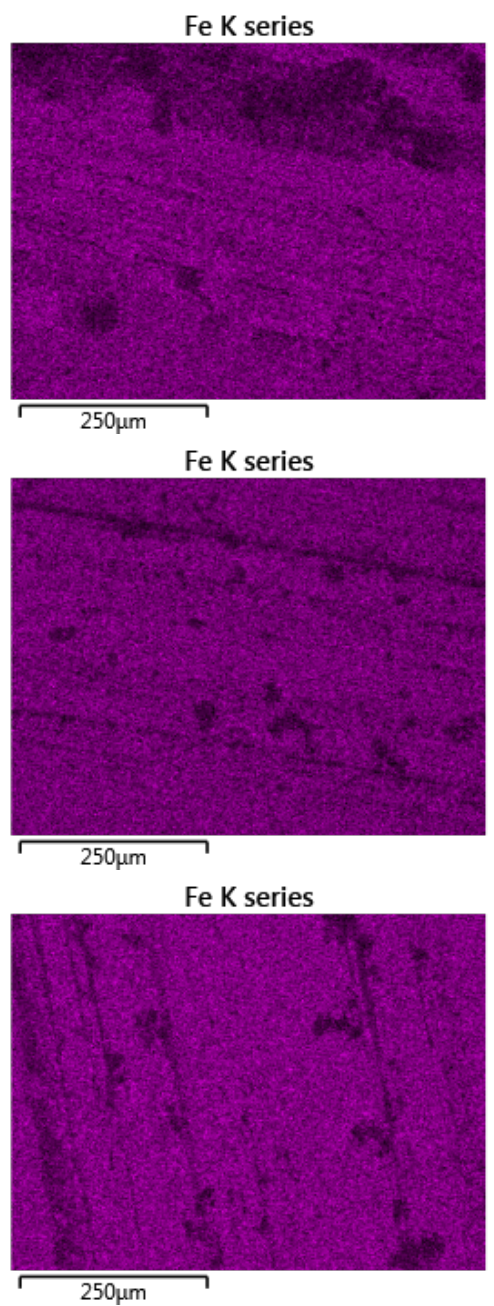
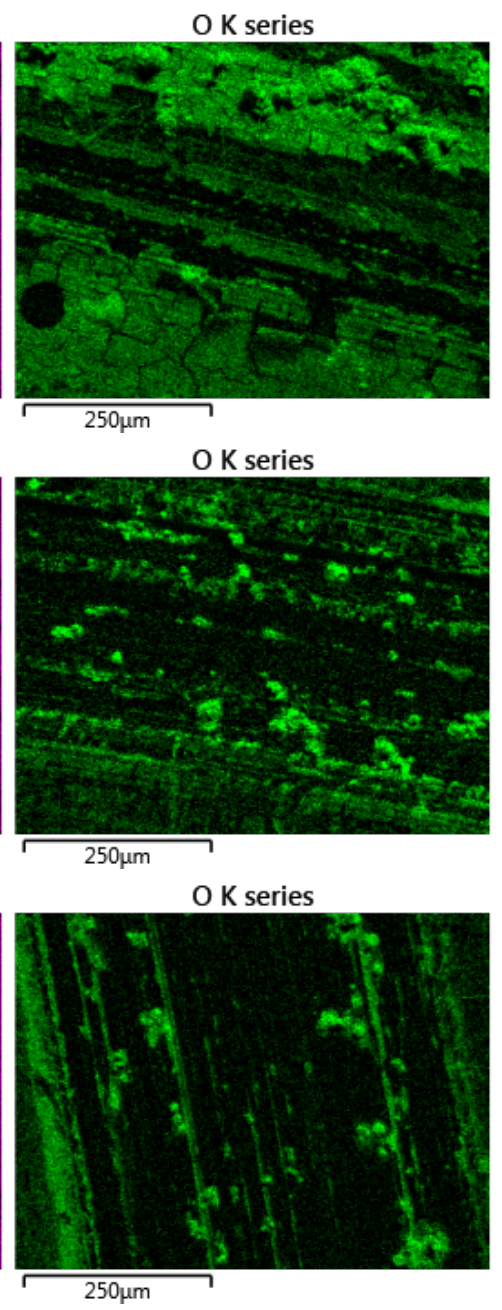

Fig. 12 SEM images and X-ray mappings of the worn surfaces of steel EH47 under loads of (a) 10 N, (b) $50 \mathrm{~N}$, and (c) $100 \mathrm{~N}$ in $3.5 \mathrm{wt} \% \mathrm{NaCl}$ solution. 
As is well known, pearlite in steel consists of ferrite and cementite. It has been reported that the presence of high amount of cementite in pearlite microstructure deteriorates the corrosion resistance of steel [14, 26]. The main reason is that the galvanic microcells are generated between ferrite and cementite due to the electrochemical potential difference when the steel is immersed in $\mathrm{NaCl}$ solution [1]. In contrast, bainitic steel exhibits a higher corrosion resistance than that of pearlitic steel [27]. On one hand, a lower carbon content in bainitic steel can reduce the amount of cementite [28]. On the other hand, ferrite has higher activity and dissolution rates than the bainite [29]. As can be seen in Fig. 1, steel EH36 consists of ferrite and pearlite, while steel EH47 is composed of ferrite and bainite. It should be noted that EH36 owns more ferrite than EH47. It is thus certainly clear that steel EH47 outperforms steel EH36 in the corrosion resistance. The corrosion rates obtained from polarisation curves (see Fig. 4) can also support this view. As a result, a larger number of corrosion products $(\gamma-\mathrm{FeOOH})$ are generated in the wear track of steel EH36, compared to those obtained in steel EH47. The X-ray mappings shown in Figs. 11 and 12 compare the different amounts of corrosion products when sliding against different steel disks. As shown in Fig. 12c, in particular, $\gamma$-FeOOH-depleted region can be observed in the wear track of steel EH47, which further supports its higher corrosion resistance than that of steel EH36. Therefore, the presence of considerable corrosion products during tribocorrosion process leads to lower COF values than those obtained in pure mechanical wear (see Fig. 8b), as the abundant lath hydroxides ( $\gamma$-FeOOH) can separate the ball and disk from direct contact. However, relatively less corrosion products may plough on the steel surface, which enables higher COF values instead (see Fig. 8d). The presence of severe scratches with similar sizes to the $\gamma$-FeOOH bumps shown in Fig. 12b and c, provides an evidence of this phenomenon. When sliding on the same disk under the same load, as shown in Fig. 10, tribocorrosion in $\mathrm{NaCl}$ solution induces higher total disk wear than that caused by pure mechanical wear in water for both EH36 and EH47 due to the synergistic effects of corrosion and wear. Tribocorrosion on EH36 exhibits lower disk wear than that of EH47 because of the anti-wear ability of $\gamma$-FeOOH.

\section{Conclusions}

In this study, ball-on-disk tribocorrosion tests were conducted in a $3.5 \mathrm{wt} \% \mathrm{NaCl}$ saline solution under varying loads using two different hull steels (EH36 and EH47). The influences of load and microstructure on the tribocorrosion behaviour of these two hull steels were examined in terms of the COF and disk wear. The conclusions were drawn below.

(1) The corrosion products generated during tribocorrosion process are primarily composed of lath lepidocrocite $(\gamma$-FeOOH) with residual $\mathrm{NaCl}$ crystals.

(2) Tribocorrosion on steel $\mathrm{EH} 36$ in $\mathrm{NaCl}$ solution results in lower COF values than those obtained in water, due to the formation of considerable hydroxide particulates and films with small sizes. 
(3) Tribocorrosion on steel $\mathrm{EH} 47$ in $\mathrm{NaCl}$ solution leads to higher $\mathrm{COF}$ values than those obtained in water, which is ascribed to ploughing of hydroxides with small amounts and big sizes.

(4) A higher corrosion resistance in steel EH47 enables higher COF and disk wear than those obtained in steel EH36, owing to less corrosion products generated.

(5) The synergistic effects of corrosion and wear in tribocorrosion cause much higher total disk wear, compared to that obtained under pure mechanical wear in water.

\section{Acknowledgements}

The authors are very thankful for financial support from Natural Science Foundation of China (NSFC) under the projects of Nos. 51474127 and 51671100 . The authors also appreciate the financial supports from the State Key Laboratory of Metal Material for Marine Equipment and Application (SKLMEA) and University of Science and Technology Liaoning (USTL) under the co-projects of No. SKLMEA-USTL 2017010 and No. SKLMEA-USTLN 201905. The authors wish to thank Mr. Stuart Rodd and other technicians in the workshop of SMART Infrastructure Facility at University of Wollongong (UOW) for their great support on samples machining. We finally would like to extend special thanks to Dr. David Mitchell on TEM observations at Electron Microscopy Centre (UOW), Dr. David Wexler on XRD testing at UOW, and Dr. Bintao Wu on Electrochemical testing at UOW.

\section{References}

[1] Y. Liu, J.M.C. Mol, G.C.A.M. Janssen, Corrosion reduces wet abrasive wear of structural steel, Scr. Mater. 107 (2015) 92-95.

[2] A. López-Ortega, R. Bayón, J.L. Arana, A. Arredondo, A. Igartua, Influence of temperature on the corrosion and tribocorrosion behaviour of High-Strength Low-Alloy steels used in offshore applications, Tribol. Int. 121 (2018) 341-352.

[3] A. Trausmuth, M. Rodríguez Ripoll, G. Zehethofer, T. Vogl, E. Badisch, Impact of corrosion on sliding wear properties of low-alloyed carbon steel, Wear 328-329 (2015) 338-347.

[4] Y. Zhang, X. Yin, J. Wang, F. Yan, Influence of microstructure evolution on tribocorrosion of 304SS in artificial seawater, Corros. Sci. 88 (2014) 423-433.

[5] M.R. Bateni, J.A. Szpunar, X. Wang, D.Y. Li, Wear and corrosion wear of medium carbon steel and 304 stainless steel, Wear 260(1) (2006) 116-122.

[6] P. Murkute, J. Ramkumar, S. Choudhary, K. Mondal, Effect of alternate corrosion and wear on the overall degradation of a dual phase and a mild steel, Wear 368-369 (2016) 368-378.

[7] D. Zenebe, S. Yi, S.S. Kim, Sliding friction and wear behavior of Fe-based bulk metallic glass in 3.5\% $\mathrm{NaCl}$ solution, Journal of Materials Science 47(3) (2012) 1446-1451.

[8] B.A. Obadele, A. Andrews, M.B. Shongwe, P.A. Olubambi, Tribocorrosion behaviours of AISI 310 and AISI 316 austenitic stainless steels in 3.5\% NaCl solution, Materials Chemistry and Physics 171 (2016) 239-246.

[9] L. Mao, M. Cai, G. Wang, Effect of rotation speed on the abrasive-erosive-corrosive wear of steel pipes against steel casings used in drilling for petroleum, Wear 410-411 (2018) 1-10.

[10] A. Berradja, F. Bratu, L. Benea, G. Willems, J.-P. Celis, Effect of sliding wear on tribocorrosion behaviour of stainless steels in a Ringer's solution, Wear 261(9) (2006) 987-993. 
[11] M. Stemp, S. Mischler, D. Landolt, The effect of mechanical and electrochemical parameters on the tribocorrosion rate of stainless steel in sulphuric acid, Wear 255(1) (2003) 466-475.

[12] Z. Li, J. Zhao, H. Wu, F. Jia, Y. Yao, Q. Zhang, S. Jiao, Z. Jiang, Experimental investigation on the mechanical and tribological coupled behaviour of bimetal composite under different states, Surf. Topogr.: Metrol. Prop. 7(2) (2019) 025015.

[13] G. Fargas, A. Mestra, A. Mateo, Effect of sigma phase on the wear behavior of a super duplex stainless steel, Wear 303(1) (2013) 584-590.

[14] J. Guo, S. Yang, C. Shang, Y. Wang, X. He, Influence of carbon content and microstructure on corrosion behaviour of low alloy steels in a Cl- containing environment, Corros. Sci. 51(2) (2009) 242251.

[15] A.P. Moon, S. Sangal, S. Layek, S. Giribaskar, K. Mondal, Corrosion Behavior of High-Strength Bainitic Rail Steels, Metallurgical and Materials Transactions A 46(4) (2015) 1500-1518.

[16] V. Chaudhry, S.V. Kailas, Fretting studies on self-mated stainless steel and chromium carbide coated surfaces under controlled environment conditions, Wear 301(1) (2013) 524-539.

[17] M.O.A. Mokhtar, The effect of hardness on the frictional behaviour of metals, Wear 78(3) (1982) 297304.

[18] H. Wu, J. Zhao, W. Xia, X. Cheng, A. He, J.H. Yun, L. Wang, H. Huang, S. Jiao, L. Huang, S. Zhang, Z. Jiang, A study of the tribological behaviour of $\mathrm{TiO} 2$ nano-additive water-based lubricants, Tribol. Int. 109 (2017) 398-408.

[19] H. Wu, F. Jia, J. Zhao, S. Huang, L. Wang, S. Jiao, H. Huang, Z. Jiang, Effect of water-based nanolubricant containing nano-TiO2 on friction and wear behaviour of chrome steel at ambient and elevated temperatures, Wear 426-427 (2019) 792-804.

[20] H. Wu, J. Zhao, X. Cheng, W. Xia, A. He, J.-H. Yun, S. Huang, L. Wang, H. Huang, S. Jiao, Z. Jiang, Friction and wear characteristics of $\mathrm{TiO} 2$ nano-additive water-based lubricant on ferritic stainless steel, Tribol. Int. 117 (2018) 24-38.

[21] J. Alcántara, B. Chico, J. Simancas, I. Díaz, D. de la Fuente, M. Morcillo, An attempt to classify the morphologies presented by different rust phases formed during the exposure of carbon steel to marine atmospheres, Materials Characterization 118 (2016) 65-78.

[22] L. Rapoport, V. Leshchinsky, M. Lvovsky, I. Lapsker, Y. Volovik, Y. Feldman, R. Popovitz-Biro, R. Tenne, Superior tribological properties of powder materials with solid lubricant nanoparticles, Wear 255(7) (2003) 794-800.

[23] R.I. Trezona, D.N. Allsopp, I.M. Hutchings, Transitions between two-body and three-body abrasive wear: influence of test conditions in the microscale abrasive wear test, Wear 225 (1999) 205-214.

[24] M.R. Bateni, J.A. Szpunar, X. Wang, D.Y. Li, The effect of wear and corrosion on internal crystalline texture of carbon steel and stainless steel, Wear 259(1) (2005) 400-404.

[25] F. Ahmad, M.R. Raza, A.M.A. Rani, S.H. Jason Lo, Wear properties of alumina particles reinforced aluminium alloy matrix composite, Journal of Applied Sciences 11(9) (2011) 1673-1677.

[26] A. Moon, S. Sangal, K. Mondal, Corrosion behaviour of new railway axle steels, Transactions of the Indian Institute of Metals 66(1) (2013) 33-41.

[27] J. Guo, C.J. Shang, S.W. Yang, Y. Wang, L.W. Wang, X.L. He, Effect of Carbon Content on Mechanical Properties and Weather Resistance of High Performance Bridge Steels, J Iron Steel Res Int 16(6) (2009) 63-69.

[28] Z.F. Wang, P.H. Li, Y. Guan, Q.F. Chen, S.K. Pu, The corrosion resistance of ultra-low carbon bainitic steel, Corros. Sci. 51(5) (2009) 954-961.

[29] S. Qu, X. Pang, Y. Wang, K. Gao, Corrosion behavior of each phase in low carbon microalloyed ferrite-bainite dual-phase steel: Experiments and modeling, Corros. Sci. 75 (2013) 67-77. 